\title{
ENSINO E PESQUISA EM TURISMO NA UNIVERSIDADE DE CALGARY (CANADÁ)'
}

\author{
Lorn R. Sheehan ${ }^{2}$
}

RESUMO: Analisa o desenvolvimento da educaçào em turismo nas décadas 70 e 80, destacando as suas caracteristicas básicas, principalmente na América do Norte. Apresenta um modelo multidisciplinar para a educação turística em nível universitírio, desenvolvido na University of Calgary (Alberta, Canadá), através do seu WTERC - World Tourism Education \& Research Center, o qual desenvolve quatro tipos de cursos: bacharelado, mestrado, PhD e cursos livres. Descreve, ainda, alguns mecanismos de integração de programas de educaçào em turismo no Canadá, em âmbito regional e nacional.

PALAVRAS-CHAVE: Educação em turismo; modelo multidisciplinar; University of Calgary; Alberla; Canadá.

ABSTRACT: Locate the Turism education development in the 70's and 80's decades, and emphlasize its basic characteristics in the 90 's decade, mainly in North America. Present a multidiscipline model for the tur istic education at University level, developed at Calgary University (Alberta, Canada), through its World Tourism Education and Research Center (IVTERC). emplasizing the class levels - Bachelor, Master, PhD and free classes - and mechanisms of Turistic educational programs integration at Regional and National environment.

KEY WORDS: Tourism education: multidiscipline model; Calgary University; Alberta; Canadá.

1 Sintese de palestra proferida no "I Simpósio Latino-Americano de Docentes e Pesquisadores Científicos de Turismo", realizado de 24 a 27 de novembro de 1994, Salvador, Bahia, Brasil. Traduação de Aline (i. R. Delmanto.

2

Coordenador do World Tourism Education Research Centre, The University of Calgary, Calgary, Canadá. End. para corresp.: University of Calgary - T2N 1N4 - Calgary, Alberta, Canadá. Fax: 403 282-0095. 


\section{INTRODUÇÃO}

A década de 80 foi o marco para o ensino de Turismo e Hotelaria. No início dessa década, o turismo estava lutando pelo seu reconhecimento como força socioeconômica; a educação para o turismo ainda não era considerada essencial para o que rapidamente se transformaria na "maior indústria" mundial. Como consequiência, a atenção era dada somente ao ensino, o qual apresentava muitos problemas (JAFARI e RITCHIE, 1981). Existiam poucas organizações, associações ou fóruns onde assuntos relacionados ao ensino de turismo podiam ser debatidos e desenvolvidos

No início dos anos 90, apresenta-se um quadro radicalmente diferente O ensino e o treinamento em turismo foram reconhecidos - e até mesmo considerados prioritários - por um número significativo de governantes e instituições educacionais. Enquanto esse reconhecimento já existia historicamente em grande grau na Europa, o fenômeno da "era vindoura" certamente foi a característica do ensino de turismo na América do Norte na década de 80. No Canadá, em particular, as mudanças nas atitudes não foram menos dramáticas (POLLOCK e RITCHIE, 1990). Uma das principais caracteristicas dessa mudança foi o reconhecimento crescente da importância do ensino avançado em algumas áreas do estudo turistico. Talvez mais significante tenha sido a prioridude no ensino parua administrasáco do furismo. A indústria parece ter despertado para o fato de que os esforços em providenciar treinamento aos supervisores e "staft" da linha de frente deveriam ser balanceados com programas de ensino para atuais e futuros administradores assegurando (além de outras coisas) que o pessoal bem treinado fosse distribuido e utilizado efetivamente.

Em face desses fatos o presente texto objetiva:

a) oferecer uma revisão e um resumo das principais controvérsias, que o desenvolvimento do ensino e treinamento turistico ainda enfrentam;

b) descrever a estrutura utilizada para desenvolver o ensino de turismo na Universidade de Calgary e regiões vizinhas, que pode conter idéias interessantes para aqueles que estão iniciando ou modificando seus próprios programas.

\section{ENSINO DE TURISMO: QUESTÕES PARA A DÉCADA DE 91}

Enquanto a falta de reconhecimento, apatia e mesmo o desprezo (lo ensino de turismo caracterizava a década de 70 e começo de 80 , descobriuse, agora, um conjunto diferente de circunstâncias e questões, que inclui: a) indicar as necessidades diversas da indústria turística multidimensional;

b) determinar a importância da relação formação teórica x prática;

c) desenvolver estruturas para a esfera de programas interdisciplinares requeridos pelo turismo como um todo;

d) determinar a importância dos programas genéricos $\mathrm{x}$ programas especializados;

e) guiar os recursos humanos e financeiros necessários para desenvolver programas de qualidade;

f) assegurar a aceitação e o uso efetivo dos graduados em turismo, já que as indústrias experimentam uma maior transformação;

g) desenvolver um sistema que faça apropriadamente o equilibrio entre a educação turística e as necessidades de treinamento.

\subsection{Necessidades Diversas de Uma Indústria Multidimensional}

Os educadores estão muito atentos à natureza complexa e diversa da indústria doturismo-ou como dizem alguns "as indústrias doturismo". Neste ponto, POLLOCK (1986) identifica três grandes dimensõesdestadiversidade que precisam ser consideradas quando se criam e se desenvolvem ensino de turismo e programas de treinamento:

a) setores da indústria turística: é importante lembrar que há muitos setores dentro do turismo com diferentes necessidades de treinamento, podendose identificar os seguintes: acomodação, transporte, alimentos $\&$ bebidas, atrações e eventos, recreação e aventura, comércio de viagens e tours, convenções e shows, e serviços de apoio;

b) niveis de concentração no Turismo: o planejador educacional deve considerar vários niveis de concentração em cada um desses setores, como tamanho, escala e sofisticação. Na verdade, tais niveis devem ser considerados parcialmente, pois variam significativamente de uma região para outra, onde as necessidades de conhecimento e treinamento também variam. Por ser impossivel encontrar todas as necessidades(ou demandas) específicas de cada setor da indústria e do nivel de concentração dentro de cada setor, é importante que se formule uma estratégia educacional que identifique pontos em comum; 
c) niveis da atividade de emprego: dentro de cada setor há numerosos serviços e seus niveis podem ser destinguidos na base da atividade (CHOY E GEE 1978). O presente modelo mostra quatro niveis

- Linha de fiente: trabalhadores deste nivel têm atividades especificas a desenvolver, têm contato direto com o consumidor da viagem, sào normalmente novatos no ramo e requerem relativamente pouco treinamento para começar a trabalhar. Muito do aprendizado acontece durante o serviço;

- supervis(or: profissionais que supervisionam e guiam o "stalff" dentro da organização, encarregando-se de múltiplas tarefas.

- administruclor ("management"): executivos que dirigem várias equipes e precisam distribuir recursos para alcançar objetivos. O foco do treinamento em Turismo tem sido na aquisição de habilidades técnicas de administração através de experiência operacional;

- executivo sênior: definido como aqueles administradores que têm responsabilidades múltiplase únicas. Ao invés do centro da atenção se a habilidade técnica de administração, que é adquirida pela experiência e que envolve contato pessoal e direto com os subordinados, executivo sênior deve analisar problemas complexos e desenvolver uma gama enorme de habilidades conceituais e organizacionais.

\subsection{Orientação Teórica x Prática}

Freqüuentemente discussões sobre o desenvolvimento de programas turisticos recaem em argumentações que questionam até que ponto os programas teóricos - modelo das universidades tradicionais - preenchem as necessidades da indústria. Apesar da popularidade desta discussão, ela não é um debate valioso

O ensino do turismo deve atender bem as necessidades de ambas (indústria/universidade). Isso não significa que cada educador e cada instituição de ensino precisa ser individualmente teórico(a) e prático(a). Apesar disso, alguns individuos e/ou organizações, e particularmente o sistema como um todo, precisam efetivamente atender ambas as dimensões.

No presente, pelo menos na América do Norte, parece que a orientação profissional é muito dominante. Os educadores, de um lado, sempre falharam em proporcionar a visão e a liderança necessária para se desenvolver uma infra-estrutura que respondesse adequadamente às necessidades da indústria turistica. De outro lado, a indústria sempre demostrou ter pouca visão por insistir em programas que proporcionassem "habilidades práticas" imediatamente aplicadas a necessidades especificas. O ensino do Turismo tem que ser relevante, mas também tem que ser formação. É necessário ter em mente a necessidade de desenvolver na indústria a capacidade de generalizar, de "aprendera aprender", de sercriativamente funcional frente anovas situaçōes e de iniciar algo sem aquele medo paralisante do desconhecido.

Para atingir esse objetivo, os programas educacionais devem-se basear em estruturas conceituais sólidas e relevantes. O desenvolvimento e a atualização dessas estruturas requerem um questionamento constante, visando seu aperfeiçoamento. Isso, é claro, demanda um contínuo processo de pesquisa e investigação científica - atividades que muitos profissionais da áreade turismo consideram irrelevantes. Essenãoé ocasoem outras indústrias (como as de petróleo, agricultura e silvicultura), onde a pesquisa, e a pesquisa baseada em programas educacionais, é parte importante e integrante da prática. Felizmente, isso parece vir acontecendo no turismo. No Canadá, o recém criado Canadian Tourism Research Institute reflete o reconhecimento formal e crescente da necessidade de rigorosas pesquisas como base para o pleno desenvolvimento da indústria na área.

\subsection{Natureza Inter e Multidisciplinar do Turismo}

Uma comprensão do fenômeno turistico requer discernimento em uma gama de diversas disciplinas. Esse fato tem uma importância considerável para a elaboração e o desenvolvimento de programas educacionais na área (JAFARI e RITCHIE, 1981), incluindo implicaçōes várias, sendo as mais significativas as seguintes:

a) necessidade de uma verdadeiraorganização multidisciplinar para o ensino dos "estudos turisticos";

b) dificuldades experimentadas dentro da estrutura institucional existente para se estabelecer a multidisciplinaridade nos estudos turísticos;

c) falta de profissionais com conhecimento teório e experiência profissional paraestudar e ensinar turismo a partir de uma perspectiva multidisciplinar;

d) falta de recursos financeiros para manter um centro ideal de estudos multidisciplinares do turismo;

e) rigidez das instituições existentes que relutam em realocar recursos de programas já existentes, mesmo que estes estejam em declinio.

\section{Ess}

universitánas estão tentando acomodar algumas iniciativas emergentes de estudo do Turismo. Essencialmente, a solução mais comum tem sido colocar o programa dentro de um curso já existente (como Ciências Sociais ou Administração). Uma alternativa que vem sendo testada na University of 
Calgary, baseou-se na criação de um Comitê Inter-Faculdades de Estudos Turísticos. Esse Comitê formou a base para o estabelecimento de um centro de pesquisa e educação multidisciplinar, o qual é discutido no item 3 deste trabalho.

\subsection{Programas Genéricos x Programas Especificos}

O campo do ensino da Administração ("Management") tem sido constantemente taxado como aquele que deveria ensinar conhecimentos administrativos genéricos em oposição aos campos mais diretamente relacionados ao meio ambiente industrial, dentro do qual serão aplicados. A emergência de sucesso do North American "Business School" após a Segunda Guerra Mundial, foi baseada na premissa de que conceitos gerais de administração, habilidades e técnicas são universais e que nenhuma ênfase particular precisa ser colocada na área de aplicação. O impacto que essas Faculdades de Administração tiveram, e sua corrente popularidade entre os estudantes, oferecem bases convincentes para a idéia do ensino "genérico" de Administração.

Dito isso, há claros problemas com o ensino genérico. O tradicional título MBA, que tende a idolotrar a educação do "administrador genérico". provocou uma desaprovação em relação à inabilidade de seus portadores em analisar profundamente as diferenças reais em administrar uma cadeia de hotéis e uma companhia de aço. A falta de capacidade em entendere relacionar os processos e culturas de uma indústria especifica tem causado a ruína de talentosos profissionais. $\mathrm{Na}$ indústria turística, o sucesso comprovado de instituições como a Cornell Hotel Scholl nos Estados Unidos evidencia que uma formação forte e centralizada pode ser muito efetiva em fornecer administradores para um segmento especial da indústria.

Apesar disso, alguns argumentam que a orientação de uma escola de Hotelaria pode ser expressa através de uma perspectiva turistica. Enquanto antigamente isso pode não ter sido uma preocupação séria em nível prático. contribuiu para a fragmentação e o isolamento dos setores da indústria. Para o futuro, há um esforço crescente em se visualizar o turismo um sistema total que requer uma abordagem adminstrativa integrada (MILL e MORRISON. 1985). Sob essa abordagem, o meio termo ente a formação genérica e a formação especifica torna-se evidente.

O conhecimento profundo de uma indústria complexa e diversa $e$ certamente desejável, mas, ao mesmo tempo, os profissionais precisam ter a capacidade de lidar e integrar várias situações e organizações - toda a capacidade requerida de um administrador ou gerente geral.
Nãohá certamente uma solução certa para esse dilema. A resposta óbvia éque uma variedade de soluçōesirãoemergir, incluindo os atuais adminstradores éque uma (MBA) e os adminstradores especificos de setores. Também genéricos (MBA) e de uma solução intermediária que será caracteaparecerá a necessidade real de uma solução intermediária que sera caracte-
rizada como o administrudor gerul com conhecimentos inchustricis especifi$\cos$.

\subsection{Administração de Recursos Humanos e Financeiros}

Governantes, indústria e instituições educacionais acordaram para a necessidade e importância da educação e treinamento em turismo. Infelizmente, eles nem sempre têm respondido a essa necessidade com recursos adequados à magnitude de tal tarefa. Enquanto cada país e cada região encontra-se em diferentes circunstâncias, pode-se afimmar que o ensino do turismo é excessivamente mal financiado em comparação à sua importância econômica e a outros segmentos da indústria.

Hoje existem programas educacionais e de pesquisa que mantêm todos os setores da economia, com exceção do turismo. Para a indústria turística é simplesmente irreal fingir que é capaz de manter uma infra-estrutura educacional cara, dando ao mesmo tempo retorno aos investidores e empresários, do mesmo modo que fazem outras indústrias. Governantes reconheceram a importância do turismo, e eventualmente respondem com financiamentos apropriados para o ensino da atividade. O papel dos educadores é, portanto, o de fazer todo o possível para acelerar o processo de desenvolvimento e consolidação dessa infra-estrutura.

Mesmo que os problemas financeiros en fretados pela área de educação do turismo sejam resolvidos, ainda ter-se-á o enorme desafio de encontrar, em número suficiente, professores e administradores competentes para trabalhar nos programas existentes ou em elaboração. Como já citado, o professor/ administrador ideal para um programa de nivel universitário deve possuir treinamento formal e experiência prática. A experiência é necessária para assegurar que os programas sejam pertinentes; treinamento formal é essencial quando se propõe a educar para as necessidades de amanhã e não para os problemas de ontem.

Tudo isso implica em uma demanda considerável de educadores que estejam familiarizados com as práticas da indústria e que tenham educação formal na área de turismo, em nivel de mestrado ou $\mathrm{PhD}$, ou seja, que focalizem o turismo como um campo de estudo. O preenchimento desta lacuna representa um grande desafio e uma grande oportunidade para instuiçōes que pretendem liderar no campo do ensino turístico. 


\subsection{Accitação dos Graduados em Turismo}

A indústria turistica é bem conhecida por sua visão tradicional de que a única rota para o topo é gal gar degrau por degrau desde a base. Enquanto esse pensamento tem o importante mérito de assegurar que oadministrador médio e sênior, realmente tenha conhecimento dos problemas enfrentados por este setor da indústria e seu "staff", ele também mostra inúmeras deficiências, tais como:

a) um pequeno setor focaliza experiência e perspectivas;

b) extrema dificuldade em proporcionar conhecimentos administrativos apropriados às pessoas no início da carreira;

c) a falta de pensamento estratégico e liderança global para a indústria.

Conforme os programas de educação e treinamento se desenvolverem. irão formar graduados que superarão essas imperfeições a médio a lonğo prazo. Como a experiência em outras áreas demonstrou (por exemplo, no setor bancário), a evolução da indústria irá ocorrer, porém não sem algumas "dores de crescimento". A transição para o profissionalismo é e será dificultada por aqueles que se sentem ameaçados pela entrada de profissionais inovadorese com energia, os quais têm alta capacidade de competição e grandes perspectivas. Esses graduados pioneiros irão en frentar os mesmos problemas que seus antecessores em outras áreas.

Apesar deste pequeno período, a "nova onda" irá prevalecer e o turismo tornar-se-á profissionalmente reconhecido. O papel do educador é assegurar que essa transição seja o mais efetiva e indolor possivel. lgualmente, precisase assegurar que o "sistema educacional total" considere os requisitos e necessidades da indústria em nível operacional. Por causa distoé provável que muitos programasenvolvam componentes básicos que permitirão ao estudante lucrar com a experiência prática da indústria.

\subsection{Equilíbrio e Integração de Programas}

A ênfase na educação em turismo tem sido mormente centrada no treinamento. Conseqüentemente, a educaçãode administradorese supervisores sêniors tem atrasado bastante o treinamento do "staff" da linha de frente. Para se corrigir esta situação é necessário que se façam esforços para balanceíl constantemente os recursos destinados à educação turistica, ou seja, estes devem ser distribuidos em todos os niveis do sistema.
Esta última questão da integração de programas em todos os níveis do sistema de ensino/treinamento é particularmente importante e precisa se mencionada de uma maneira especial. A postura especifica da Universidade de Calgary na área de Turismo e Hospitalidade é vista em detalhe a seguir.

\section{UM MODELO PARA EDUCAÇÃO EM TURISMO}

As idéias sobre treinamento e ensino do turismo, discutidas no item 2 , fundamentaram a estrutura dos programas criados e desenvolvidos na Universidade de Calgary (Alberta, Canadá). Pelas reações iniciais de outros colegas e outras regiōes, parece que omodeloque está sendoimplantadoé de interesse para quem está pensando em estabelecer ou desenvolver seus próprios programas. Apresenta-se essa estrutura a partir de três componentes principais:

a) um modelo de programa avançado multidisciplinar em nivel universitário para o ensino do turismo;

b) um mecanismo de coordenação e integração dos programas de turismo, permeando todos os níveis do sistema de ensino e treinamento dentro da região;

c) mecanismos nacionais e regionais para coordenar e integrar os programas turisticos

\subsection{Modelo Multidisciplinar para um Programa de Nível}

\section{Universitário}

A organização "guarda-chuva" para coordenação da criação e distribuição dos programas turísticos na Universidade de Calgary é o World Tourism Education and Research Center - WTERC. Como o próprio indica, esse centro esforça-se para dar uma perspectiva global aos seus programas de pesquisa e educação. Tenta, dentro dos limites dos recursos disponíveis, fornecer um completo portfólio dos programas turisticos avançados que envolvem componentes multidisciplinares em vários niveis, todos apropriados à Universidade.

O WTERC, estabelecido sob a autoridade do Presidente, procura e propar iniciativas de estudos turísticos existentes dentro da Universidade As porcionar um fórum para o planejamento de iniciativas futuras na área. As atribuições especificas do WTERC são: 
a) fornecer um veículo para a troca regular de informaçōes em todas as faculdades e departamentos com relação a programas correntes, programas propostos e iniciativas no campo de estudos turísticos;

b) fornecer um mecanismo de coordenação de ensino, pesquisa e atividades de extensão em turismo, nas várias faculdades e departamentos na Universidade de Calgary;

c) fornecer um veículo pelo qual a Universidade de Calgary poderá formalmente relacionar-se com organizaçōes externas no campo do turismo;

d) promover o reconhecimento da existência e da qualidade do ensino, pesquisa e extensão em turismo na Universidade de Calgary.

Para manter uma perspectiva realista, deve-se notar que o WTERC (incluíndo seu antecessor, o Comitê de Estudos Turísticos Inter-Faculdades) só existe há cinco anos. Durante este período, seu impacto foi modesto, porém útil. Do lado positivo, constituiu-se em um um veículo, reconhecido pela Universidade para coordenar todos os trabalhos turísticos na campus, facilitar a comunicaçào entre as unidades acadêmicas interessadas e interagir com unidades/organizaçōes externas. Um beneficio bastante concreto foi a preparação das propostas integradas ao governo para o financiamento e desenvolvimento de programas. Essas propostas foram favoravelmente recebidas, sendo que recursos substanciais para o desenvol viento de programas estão por vir. Além disso, os esforços concentrados de membros do centro levou-o a ser reconhecido pela Organização Mundial de Turismo (OMT) como um dos doze membros do importante corpo de redes de ensino, treinamento e pesquisa intemacional. Do lado menos positivo, há vários níveis de interesse e promessas para a "causa" doturismo. Oresultado óbvio deste fato é que núcleos de faculdades têm programas ativos que fornecem forças dirigentes que se submetem às atividades do Comitê. Apesar disto. a participação de patrocinadores periféricos tem sido surpreendentemente boa.

A tabela a seguir (Tabela 1) identifica as disciplinas que podem ser consideradas o núcleo componente do WTERC. Isso inclui a Educaça Continuada, Estudos Gerais (Artes e Ciências), Ciências Socias, Educaçào Física, Administração e Planejamento Ambiental. Há quatro niveis de programa: Bacharelado, Mestrado, $\mathrm{PhD}$ (ou doutorado), nào-graduado (Certificado). Como pode ser visto, cada uma destas unidades contém de um a quatro niveis de programas
Tabela 1 - The University of Calgary World Tourism Educaiton \& Research Centre - Modelo Muldisciplinar para Programas Universitários em Turismo

\begin{tabular}{|c|c|c|c|c|}
\hline \multirow[b]{2}{*}{ FACULI)AIDE } & \multicolumn{4}{|c|}{ NIVETS DO PROGRAMIA } \\
\hline & Bacharelado & Mestrado & Ph.l) & $\begin{array}{l}\text { Cursos } \\
\text { Llyres }\end{array}$ \\
\hline Educação Continuaula & & & & $x$ \\
\hline Estudos Gerais & $x$ & $\mathrm{x}$ & & \\
\hline Ciências Sociais & $x$ & & & \\
\hline Educação Fisica & $x$ & & & \\
\hline Administração & $\mathrm{x}$ & $x$ & $x$ & $x$ \\
\hline Planejamento Ambiental & & $x$ & & $x$ \\
\hline
\end{tabular}

Vale a pena examinar cada um desses níveis em detalhe para obter uma apreciação global de como esse programa dirige alguns dos temas tratados no item 2 deste trabalho.

\subsubsection{Bacharclado}

Existem duas estruturas em nivel de bacharelado. O programa de Bacharelado em Comércio, Administracuão Turistica e Hoteleira, e o programa de Bacharelado em Artes, Lazer Tirristico e Sociedacle. Além dissso, os estudantes podem fazer cursos individuais em outras Faculdades como as de Ciências Sociais e Educação Física.

O programa de Bucharelaclo em Comércio, Administrașũo Turistica e Hoteleira dura quatro anos e visa o desenvolvimento de administradores júniors. Proporciona o desenvolvimento de conhecimentos nas áreas de finanças, marketing, recursos humanos, sistemas de informaçōes e administração operacional . Além disso, cursos específicos são ministrados nas áreas de Turismo e Administração Hoteleira. A intenção do programa é formar pessoas com fortes habilidades administrativas/gerenciais e com bom conhecimento do sistema turístico como um todo. Aos estudantes também é dada a oportunidade de obter experiência prática através de um convênio firmado com empresas e entidades da área.

O programa de Buchareluclo em Artes. Lazer Tiristico e Socieducle, também dura quatro anos. Este programa é verdadeiramente muldisciplinar, por natureza. Os cursos oferecidos são extraidos de diferentes faculdades e 
por isso, refletem uma variedade de visões tanto da sociologia, como da recreação e da administração. A intenção deste programa é desenvolver profissionais com uma visão macro do turismo. O curso é um excelente ponto de partida para quem quer trabalhar junto ao governo ou iniciar estudoj cientificos na área.

\subsubsection{Mestrado}

Existem duas estruturasem nivel de mestrado: o Mestrado em Administração de Negócios (MBA) e o Mestrudo em Planejamento Ambientul. Adicionalmente, oTurismo pode ser estudado por uma perspecti va disciplinar tradicional. Exemplos incluem o Mestrado em Geografia, Economia ou Sociologia, com ênfase em Turismo.

Aqueles que querem seguir uma carreira administrativa devem fazer isso através do MBA. Este programa é elaborado para dar aos participantes uma educação administrativa sólida, combinada com um número suficiente de cursos que darão aos estudantes uma visão real e profunda da indústria turística. O MBA pode ser feito em dois anos (periodo integral) ou em quatro (meio período). Assim, o programa torna-se acessivel a profissionais que trabalham em periodo integral.

O Mestrado em Planejamento Ambiental desenvolveu-se ao longo de duas linhas principais. A primeira dirige-se ao planejamento regional sob uma perspectiva turística, enquanto a segunda enfatiza as questões do meio ambiente. Este programa, que tem duração de dois anos, dirige-se àqueles estudantes que querem ocupar postos de alto nivel no governo ou seguir carreiras especializadas dentro da indústria turística. Atualmente, esforço têm sido feitos para integrar os dois programas de mestrado, proporcionando aos mestrandos u $m$ conteúdo balanceado com características administrativas e ambientais.

\subsubsection{PhD}

É em nivel de PhD que o WTERC espera dar uma significante, e talvez maior, contribuição para o desenvolvimento do estudo do turismo, nos próximos anos, especificamente na área da Administrus:ão Turistica. O PhD em Administração permite uma especialização em Administração Turisticu e Hoteleira relacionada às várias funções de cada área do negócio. Mais uma vez, a maneira singular como o assunto é tratado formará futuros professores e pesquisadores com um conhecimento sólido de suas áreas de administraçàol gerenciamento além de proprocionar-lhes umá visão acadêmica do Turismo e da Hotelaria

\subsubsection{Cursos Livres}

Finalmente, o WTERC desenvolveu vários programas para o profissianal da indústria turística que deseja obter ou iniciar sua educação formal, enquanto continua trabalhando em tempo integral. Estes cursos oferecerem programas na área de Administruşũo Turistica e Hoteleira, e dois tipos de programas executi vos: um em Administrașão de Destinos Turísticos e o outro em Planejamento e Desenvolvimento de Turismo Rural e Comunitário.

O programa de Administrușão Turistica e Hoteleira foi elaborado para supervisores e administradores de nivel júnior e médio, que desejam desenvolver sua capacidade gerencial e seu conhecimento, proporcionando-lhes um progresso na carreira. O curso é dado por profissionais da indústria que têm uma bagagem prática acentuada. Otempo de duração é de doisanos, com aulas em um período, resultando em um certificado.

Oprogramade A (lministruşão de Destinos Turisticos foi elaborado para os executivos e administradores sêniors. Este programa é ministrado em móduloscurtose intensivos de um a quatro dias, adequando-se assim à rotina ocupada destes profissionais. Os participantes buscam melhorar ou renovar seus conhecimentos relacionando os vários aspectos da indústria turística. $\mathrm{O}$ curso todo pode ser completado em dois anos.

Além desses, o WTERC desenvolveu um programa de Planejamento eDesenvolvimentode Turismo Rurale Comuni tário. Este cursoé voltadopara profissionais do setor público que precisam desenvolver o turismo em municípios e regiões, sendo este parte de todo o desenvolvimento social, econômico e cultural de uma comunidade ou região. Mais uma vez, o curso é dividido em módulos curtos e intensivos e sua duração é de dois anos.

\subsection{Mecanismos de Integração de Programas de Educação em Turismo}

A segunda dimensão do programa de turismo e hotelaria na região de Calgary foi o estabelecimento do Calgary Consortium for Tourism and Hospitality Studies (CCTHS), que surgiu da necessidade de se assegurar a coordenação e integração dos programas de ensino e treinamento para o turismo, em todos os níveis do sistema educacional, na cidade de Calgary e região. Essa integração/coordenação éparticularmente importantena interface entre os vários níveis, além de oferecer a oportunidade de se estabelecer um fórum onde todos os seus membros apresentem suas idéias e obtenham o "feedback". Tem a seguinte missão: 
Fornecer a estrutura dentro da qual a elaborasiono, o desenvolvimento. promoçào e a distribuiçio de programas de treinamento e ensino de turis mo hotelaria em Calgary possam ser coordenados dentro de uma maneira conope. rativa e complementar. fazendo com que se alcance qualidade, reputasào impacto com esses programas. (CCTHS, 1987)

Para se cumprir esta missão, é requerida a representação de todas as instituições educacionais (escolas de $1^{\circ}$ e $2^{\circ}$ graus, instituições técnicas e universidades), indústrias, associações industriais e governo. Com seis ano de ativa operação, o CCTHS provou ser um mecanismo extremamente úti para chamar a atenção para o turismo e a hotelaria, facilitando discussões de como os esforços para o ensino do turismo podem ser efetivamente racionalizados a fim de produzir um efetivo e eficiente sistema de ensino a nivel loca e regional. Resultados concretos estão começando a emergir, por exemplo, na forma de um catálogo dos cursos e programas.

Assim, surgiu uma fusão lenta mas finme de uma "rede de competência" visivel dentro da região de Calgary. Esta concentração de "know-how" está provando ser altamente complementar e mutuamente solidária, pois permite responder, de uma certa maneira, a praticamente todas as necessidades de ensino e treinamento do setor turístico.

É preciso ainda ressaltar que o conceito desse organismo foi desenvolvido como complemento para uma iniciativa do governo, que estabelecia un Tourism Educational Council em nivel municipal. A criação deste conselho em 1987, o primeiro do gênero no Canadá (TIAALTA, 1985), representou um grande compromisso do governo de Alberta com a infra-estrutura do ensino turístico. Os objetivos do conselho são essencialmente dois: coordenar 0 desenvolvimento do sistema de ensino turístico na região e estabelecer modelos que os programas devem seguir, a fim de se obter o reconhecimento para os seus graduados (TRA VEL ALBERTA, 1986).

Até agora o Conselho concentrou seus esforços na conscientização da necessidade, para o turismo, de se ensinar e desenvolver modelos para colocação de pessoal na linha-de-frente. Apesar disso, também tem sido um importante catalisador na aceleração de tomadas de decisões com relação ao desenvolvimento de novos programas e expansão daqueles já existentes.

No âmbito nacional, o Canadian Tourism Human Resource Council foi criado em novembro de 1993, com a missão de ser um fórum para facilitaro desenvolvimento dos recursos humanos e as atividades que mantêm o nivel competitivo da indústria turistica canadense. O Departamento Federal de Recursos Humanos, Trabalho, Indústria \& Ciência está dando uma verba parı financiar despesas operacionais durante os seus três primeiros anos de seu funcionamento.

\section{CONSIDERAÇÕES FINAIS}

A partir do reconhecimento da importância do turismo para o desenvolvimento socioeconômico de várias regiões, govemantes, indústria e educadores estão agora movendo-se para providenciar a infra-estrutura que já deveria estar pronta. Como resultado, existem pressões substanciais para que se produzam resultados rápidos e se ofereçam programas que atendam às necessidades do dia-a-dia. Por isso, há a tendência em certos segmentos do setor de fazer "vistas grossas" à necessidade de bons programas em nivel avançado. O argumento parece ser: "vamos nos preocupar com o hoje que o amanliã toma conta de si". Infelizmente com esse pensamento, em quinze anos ter-se-á os mesmos problemas de hoje. A atual carência de trabalhadores no setor é apenas um sintoma do fraco sistema geral como um todo. Uma melhor administração dos recursos humanos, um melhor uso da tecnologia e da informação serão precisos se a indústria turistica quiser sobressair-se de outros setores da indústria no século XXI.

O objetivo deste trabalho foi apresentar uma estrutura dentro da qual as necessidades educacionais, em nível avançado, do setor turístico pudessem ser atendidas. A ênfase foi dada à criação de um portfólio de programas multidisciplinares e para niveis diversos. Estes programas têm três objetivos básicos:

a) atender às necessidades, de hoje e de amanhã, do ensino gerencialadministrativo;

b) aumentar o nivel de conhecimento em turismo e preparar os educadores do amanhã;

c) atentar para outros componentes do sistema educacional e de treinamento com uma visão de colaboração e cooperação, para que se assegure o desenvolvimento de um sistema eficiente e equilibrado.

Obviamente, nenhum modelo ou estrutura particular émelhor que outra ou totalmente apropriada. A estrutura exposta foi considerada útil no contexto em que se desenvolveu. Espera-se que algumas das idéias mostradas possam ser valiosas e mesmo utilizadas por outros. 


\section{BIBLIOGRAFIA}

CCTHS. 1987. Terms of rejerence for the Calgary Consortium for Tourism and Hospritality Studies. Calgary.

CHOY, Dexter; (GEE, Chyck Y. 1978. Employment oppotunities in tourism. The Cormell /folet and Restaurant Administration Quartely. Nov.

GO, Frank. 1989. An holistic approach to integrating tourism in the hotel management curriculum. In: AUTUMM 1989. Symposium of the International Association of I folet Management Scholls. Proceedings.

IAWKINS, Donald E.: HUNT, John I). 1988. Travel and tourism professional educatien. Hospitality and Tourism Education, v.I, n.I.

JAFARi, Jafar: RITCHIE, J. R. Brent. 1981. Toward a framework for tourism education. Annals of Tourism Research, v.8, n.l.

MILL, Robet (hristie; MORRIS( )N, Alastair M. 1985. The tourism system. I'rentice Ilall: New Jersey.

POLLOCK, Ann. 1980. Tourism. The quest forprofessionals. Tourism Research Group. British Columbia: Vancouver.

POLLOCK, Ann; RITCHIE, J. R. Brent. 1990. In pursuit of professionalism. An integrated strategy for tourism education training. Annals of Tourism Research.

RITCHIE, J.R. Brent. 1988. Alternative approachestoteaching tourism. In: INTERNATIONAL CONFERENCE TEACHINC'TOITRISMINTO INTO THE 1990'S. University of Surrey, U. K..

TIAALTA. 1985. A framework for the establishment of the Alberta Tourism/Hospitality Institute. Calgary: Tourism Industry Association of Alberta.

TRA VEL ALBERTA. 1986. The Alherta tourism/iospitality education stydy. Edmonton. 